\title{
Research on Variable Factors of Service Industry Growth Gaps----Take Tianjin as an example
}

\author{
Bao Jianbo ${ }^{1,}$, , Wu Peng ${ }^{2, b}$ \\ ${ }^{1}$ Dr. Bao Jianbo, Associate Professor and the head of the Department of Economics of School of \\ Economics of Tianjin Polytechnic University, Tianjin, 300387, China \\ ${ }^{2}$ Student of Department of Economics of School of Economics of Tianjin Polytechnic University, \\ Tianjin, 300387, China \\ aemail: baojianbo1201@126.com, bemail: wupeng8263820@163.com
}

Keywords: Service Industry; Shift-Share Method; Industrial Structure

\begin{abstract}
The paper takes Tianjin as an example, analyzes the service industrial structure and the industry competitiveness by using the shift-share method. The conclusion is: Tianjin service industry has a growth advantage; we should pay more attention to the development of it. But there are two problems: The internal structure is not reasonable and the competitiveness is weak, which is caused by the market structure, industrial layout etc. Therefore, it is necessary to optimize the service industry structure. The paper gives the optimizing suggestions. Tianjin's experience has some enlightenment to the similar city to develop service industry.
\end{abstract}

China's "Twelfth Five Year Plan" proposed Tianjin should focus on the development of advanced manufacturing industry. Then should Tianjin also pay attention to the service industry and promote the city development with the development of the service industry? This paper analyzes the growth disparity factors of Tianjin service industry by using the shift-share model. Then proposes Tianjin should focus on the service industry and readjust the industrial structure.

\section{The shift-share method and the model}

Shift-share method is also called SSM model. It has become the basic method for analyzing the difference of regional growth determinants. This method is decomposed into three components: the national share (NS), the industrial mix effect (IM) and the regional shift (RS) [1]. NS measures an industry should achieve the growth amount in accordance with the national growth rate. IM and RS explain a certain industry of regional and national development deviation factor [2].

The domestic research on this method is emerged after 2000, most of them inspect the regional industry development and target manufacturing industry, there is not analysis on the service industry [3][4]. The innovation of this paper lies in the dynamic review of the development of service industry in Tianjin by using SSM.

Assume the gross products and the structure of Tianjin service industry have changed after the time of $[0, t]$. Suppose the base sector of total size of it is $b_{0}$ (use the service industry gross output value represent), the end stage (by year $t$ )of total size of it is $b_{t}$. Divide Tianjin service industry into $n$ industries, named $b_{j, 0} \cdots \cdots b_{j, t}(j=1,2, \cdots \cdots n)$, expresses the scale of No.j industry of the initial and the end period, using $\mathrm{B}_{0}, \mathrm{~B}_{\mathrm{t}}$ represent the total size of the early and late period of the economy, using $B_{j 0}$ and $B_{j t}$ to represent the scale of No.j industry of the corresponding period of the early and the late [5].

Named the change rate of No.j service industry in the base and the reporting period as rj, then:

$$
r_{j}=\frac{b_{j t}-b_{j 0}}{b_{j 0}}(\mathrm{j}=1,2, \cdots \cdots, \mathrm{n})
$$

Named the change rate of national No.j industry in the base and the reporting period as $R_{j}$, then: 


$$
R_{j}=\frac{\mathrm{B}_{j t}{ }^{-B} j 0}{B_{j 0}}(\mathrm{j}=1,2, \cdots \cdots, \mathrm{n})
$$

Make the scale of every Tianjin industry standard by using various industrial sectors of national service industry share, we can obtain:

$$
b_{j}^{\prime}=\frac{b_{j 0} \bullet B_{j 0}}{B_{0}}(\mathrm{j}=1,2, \cdots \cdots, \mathrm{n})
$$

So, in the time of $[0, t]$, the growth rate of Tianjin No. $j$ service industry Gj can be decomposed into $\mathrm{Nj}, \mathrm{Pj}$, $\mathrm{Dj} 3$ component, specific expression:

(4)

$$
\mathrm{G}_{j}=N_{j}+P_{j}+D_{j}
$$

(5)

$$
\mathrm{N}_{j}=b_{j}^{\prime} \times R_{j} \quad P_{j}=\left(b_{j 0}-\mathrm{b}_{\mathrm{j}}^{\prime}\right) \times \mathrm{R}_{\mathrm{j}} \quad, \quad D_{j}=b_{j 0} \times\left(r_{j}-R_{j}\right)
$$

$$
G_{j}=b_{j t}-b_{j 0}
$$

(6)

$$
P D_{j}=P_{j}+D_{j}
$$

$\mathrm{Nj}$ is the share component, refers to the changes Tianjin No. j service industry scale. $\mathrm{Pj}$ is the structure deviation component, refers to the deviation of Tianjin No. $\mathrm{j}$ service industry growth compared with the national one. $\mathrm{Dj}$ is the regional competitiveness deviation component. It includes productivity level, management level and enterprise scale structure etc. PDj reflects the total growth advantage of Tianjin No. $\mathrm{j}$ service industry.

\section{Empirical analysis}

The paper selects 2006 -- 2010 Tianjin service industry's output data to do the shift-share analysis of Tianjin service industrial structure. We choose the previous year as the base period. Based on the SSM, we can get different results, see table 1.

Table 1 The results of Tianjin service industry SSM

\begin{tabular}{|c|c|c|c|c|}
\hline Year & $\mathrm{N}_{\mathrm{j}}$ & $\mathrm{P}_{\mathrm{j}}$ & $\mathrm{D}_{\mathrm{j}}$ & $\mathrm{PD}_{\mathrm{j}}$ \\
\hline $2005 / 2006$ & 126.17 & 189.74 & -97.35 & 92.39 \\
\hline $2006 / 2007$ & 184.71 & 266.48 & -156.14 & 110.34 \\
\hline $2007 / 2008$ & 153.98 & 213.59 & 471.40 & 684.99 \\
\hline $2008 / 2009$ & 153.49 & 213.51 & 151.51 & 365.02 \\
\hline $2009 / 2010$ & 255.29 & 332.59 & 245.61 & 578.20 \\
\hline
\end{tabular}

Data sources: Calculated from Tianjin and China statistical year books

From table 1 we can see: compared with the national service industry, Tianjin has the advantage of growth. Firstly, $\mathrm{Nj}$ is more than 0 . Tianjin is growing fast; Secondly, $\mathrm{Pj}$ wave rises, indicating the contribution of Tianjin three industrial structures to the economic growth is higher. Thirdly, Dj were at the fluctuation. This show Tianjin service industry competitiveness is poor. Finally, PDj indexes are greater than 0 in different years; Tianjin service industry has a certain competitive advantage. In order to further study the various service industries, table 2 calculating the deviation from the service industry -- analysis of share index (see Page 3).

As can be seen from table 2, Tianjin service industry development is not balanced; there are gaps among the industry competitiveness. Firstly, according to $\mathrm{Nj}$ we can see: the wholesale and retail industry develop fastest, the average value of $\mathrm{Nj}$ is 10 for five years. Followed is the 
transportation, storage and postal industry, financial and real estate industry, the average value of $\mathrm{Nj}$ is 3 or so. And the average value of $\mathrm{Nj}$ of education, public management and social organization is low and stable, it is mostly 1 . The average value of $\mathrm{Nj}$ of other service industry is roughly in line with the national economy, that is 0 . Thus, the development of Tianjin service industry is slowly, most of them keep the same pace with the national economy. Secondly, from $\mathrm{Pj}$ we can see the development of Tianjin service industry structure is imbalance. The Pj value of the four industries----wholesale and retail trade, finance, real estate, transportation and warehousing postal industry is the most highest. $\mathrm{Pj}$ value of the culture, sports and entertainment is the lowest. This shows Tianjin industrial structure is irrational, the service industry development is over reliance on the four industries. The cultural industry proportion in the national economy is low; Finally, from Dj we can see the competitiveness of each service industry is weak. Each value of $\mathrm{Dj}$ of it was negative or lower positive in 2006 and 2007. In 2008-2010, most of the industry's' Dj values were positive, but had more fluctuation. [6]

Table 2 The results of SSM of internal industry of Tianjin service industry

\begin{tabular}{|c|c|c|c|c|c|c|c|c|c|c|c|c|c|c|c|c|c|c|c|c|}
\hline \multirow{2}{*}{ Industry } & \multicolumn{4}{|c|}{2006} & \multicolumn{4}{|c|}{2007} & \multicolumn{4}{|c|}{2008} & \multicolumn{4}{|c|}{2009} & \multicolumn{4}{|c|}{2010} \\
\hline & $\mathrm{N}_{\mathrm{i}}$ & $P_{i}$ & $\mathrm{D}_{\mathrm{i}}$ & $\mathrm{PD}_{\mathrm{i}}$ & $\mathrm{N}_{\mathrm{i}}$ & $P_{i}$ & $\mathrm{D}_{\mathrm{i}}$ & $\mathrm{PD}_{\mathrm{i}}$ & $\mathrm{N}_{\mathrm{i}}$ & $P_{i}$ & $\mathrm{D}_{\mathrm{i}}$ & $\mathrm{PD}_{\mathrm{i}}$ & $\mathrm{N}_{\mathrm{i}}$ & $P_{i}$ & $\mathrm{D}_{\mathrm{i}}$ & $\mathrm{PD}_{\mathrm{i}}$ & $\mathrm{N}_{\mathrm{i}}$ & $P_{i}$ & $\mathrm{D}_{\mathrm{i}}$ & $\mathrm{PD}_{\mathrm{i}}$ \\
\hline $\begin{array}{l}\text { Transportation, storage and } \\
\text { postal industry }\end{array}$ & 2 & 27 & -3 & 24 & 3 & 47 & -9 & 38 & 2 & 34 & 107 & 140 & 1 & 9 & 25 & 34 & 3 & 64 & 47 & 111 \\
\hline $\begin{array}{l}\text { Information transmission, } \\
\text { computer service and } \\
\text { software industry }\end{array}$ & 0 & 14 & -8 & 7 & 0 & 15 & -7 & 8 & 0 & 16 & 1 & 16 & 0 & 4 & 22 & 26 & 0 & 12 & 7 & 18 \\
\hline Wholesale and retail trade & 7 & 89 & -65 & 25 & 10 & 115 & -94 & 21 & 10 & 115 & 94 & 209 & 6 & 70 & 43 & 113 & 17 & 179 & 59 & 237 \\
\hline $\begin{array}{ll}\begin{array}{l}\text { Accommodation } \\
\text { catering industry }\end{array} & \text { and } \\
\end{array}$ & 0 & 10 & -1 & 9 & 0 & 12 & 1 & 13 & 0 & 17 & 0 & 17 & 0 & 8 & 14 & 22 & 0 & 17 & 8 & 25 \\
\hline Finance & 2 & 44 & -18 & 26 & 4 & 94 & 4 & 98 & 3 & 56 & 21 & 77 & 3 & 69 & 21 & 90 & 4 & 79 & 28 & 107 \\
\hline Estate & 1 & 32 & -1 & 30 & 3 & 51 & -25 & 26 & 1 & 12 & 26 & 38 & 3 & 58 & 20 & 78 & 4 & 65 & 1 & 65 \\
\hline $\begin{array}{lll}\begin{array}{l}\text { Leasing } \\
\text { services }\end{array} & \text { and } & \text { business } \\
\end{array}$ & 0 & 14 & 2 & 16 & 0 & 14 & -6 & 8 & 0 & 13 & 42 & 55 & 0 & 13 & 15 & 27 & 1 & 39 & 20 & 58 \\
\hline \begin{tabular}{lr}
\multicolumn{1}{c}{ Scientific } & research, \\
technical & services and \\
geological & prospecting \\
industry & \\
\end{tabular} & 0 & 24 & -4 & 20 & 0 & 28 & -16 & 12 & 0 & 18 & 57 & 75 & 0 & 34 & 16 & 49 & 1 & 45 & -8 & 38 \\
\hline $\begin{array}{ll}\text { Water } & \text { conservancy, } \\
\text { environment } & \text { and public } \\
\text { facilities } & \text { management } \\
\text { industry } & \\
\end{array}$ & 0 & 2 & 6 & 9 & 0 & 5 & -1 & 4 & 0 & 5 & -6 & -1 & 0 & 6 & 0 & 6 & 0 & 7 & 12 & 19 \\
\hline $\begin{array}{l}\text { Resident services and other } \\
\text { services }\end{array}$ & 0 & 9 & -1 & 8 & 0 & 9 & -1 & 8 & 0 & 13 & 73 & 86 & 0 & 23 & -21 & 3 & 0 & 27 & 2 & 29 \\
\hline Education & 0 & 12 & -3 & 9 & 1 & 20 & -2 & 18 & 1 & 18 & 9 & 28 & 1 & 26 & -1 & 25 & 1 & 25 & 8 & 33 \\
\hline $\begin{array}{l}\text { Health, social security and } \\
\text { social welfare }\end{array}$ & 0 & 5 & -1 & 4 & 0 & 9 & -3 & 6 & 0 & 8 & 19 & 27 & 0 & 8 & -2 & 6 & 0 & 15 & 1 & 16 \\
\hline $\begin{array}{lll}\begin{array}{l}\text { Culture, sports and } \\
\text { entertainment }\end{array} & \text { and } \\
\end{array}$ & 0 & 2 & 5 & 7 & 0 & 4 & -1 & 3 & 0 & 4 & 4 & 9 & 0 & 5 & 1 & 6 & 0 & 4 & 4 & 8 \\
\hline $\begin{array}{l}\text { Public management and } \\
\text { social organization }\end{array}$ & 1 & 21 & -10 & 11 & 1 & 19 & -10 & 9 & 1 & 25 & 20 & 45 & 1 & 14 & 4 & 18 & 1 & 11 & 24 & 35 \\
\hline
\end{tabular}

Data sources: Calculated from Tianjin and China statistical year books

\section{Conclusion}

From the above analysis we can know, Tianjin service industry has the advantage of internal growth and most of Tianjin service industry's development speed is close to the nations. But there are two problems: The first is the internal structure of service sector is not reasonable, the service industry development is over reliance on the four industries. The cultural industry proportion is low, restricts the development of sector structure effect to promote service industry level; the second is the competitiveness is low, which is caused by the market structure, industry layout etc.

In addition, Tianjin is the economic center of China's north coastal and the municipalities directly under our government, the development of the service industry should be much higher. So, although compared with national service industry, Tianjin has the rapid development, the development level of it is still low, hasn't given important contribution to the economic growth.

\section{Measures to promote the development of Tianjin service industry}

Firstly, we should actively promote modern service industry development and optimize the internal structure of it [7][8]. Secondly, we should deepen the reform of the management system of 
service enterprises. We need establish a scientific management system and a modern enterprise property right system to make the property rights and responsibilities clear. And we should encourage some of the strength enterprise to merge in accordance with market principles and integrate the industry. Thirdly, we need to optimize the market structure, promote the industry competition [9]. We need introduce competition and market mechanism, allow different economic subject to participate in the competition. The other is to establish the reasonable standard market rules to maintain a good market environment. We must introduce new market competition body participation. Fourthly, in order to promote the rapid development of service industry healthily, we must develop industry standards for various service industries. For example, establish the service product quality certification standards etc. The measures will help to improve the service products quality and the effective market demand and the service industry development growth. [10]

All in all, Tianjin should pay more attention to the development of service industry when develop the advanced manufacturing industry. It is necessary to find the reasons of restricting the growth of the service industry, optimize the structure of service industry, improve the competitiveness of industries and promote the economic development with the development of service industry. The experiences of Tianjin have certain enlightenment significance to other similar city in china.

\section{Acknowledgement}

In this paper, the research was sponsored by the Philosophy and Social Science Program Foundation of Tianjin (Project No. TJLJ11-012).

\section{References}

[1] Xu Jiang. Research on the optimization of industrial structure of Liaoning coastal regions [D].Wuhan: Wuhan Science and Engineering University, 2009

[2] Wu Dapeng. Analysis on the industrial structure of the southern cities in Chengyu economic zone based on shift-share method [J]. Reform of the Economic System, 2012 (6): 173 -- 176

[3] Zhang Qianxiao. Development status of Shaanxi industrial pillar industries: shift-share analysis [J]. Modern Economic Science, 2004 (5): 92 -- 96

[4] Deng Ronglin. The system environment of enterprises' independent innovation and innovation of the system [J].Journal of Management Engineer, 2010 supplement: 55 -- 56

[5] Fang Jia. Research on the industrial structure [M]. Beijing: China People University Press, 1997

[6] Fang Hui, Lv Jing, Duan Guorui. Empirical research on the industrial structure promotion effect of China's undertaking international service industry transfer [J]. Research on the World Economy, 2012 (6): 58 -- 63

[7] Bao Jianbo. Research on the area layout optimization of China's modern service industry [J]. Guizhou Social Science, 2009(10): $57-61$

[8] Bao Jianbo. The optimization countermeasures of modern service industry layout in Bohai area [J]. Macroeconomic Management, 2009 (4):37 -- 39

[9] Bao Jianbo. Binhai New Area: Develop the industrial cluster and optimize the industrial structure [J]. Macroeconomic Management, 2010 (12): 54 -- 55

[10] Jiang Xiaojuan, Li Hui. Service industry and Chinese economy: a study of the potential of economic relevance and accelerate the growth [J]. Economy Research, 2004 (1): 4 -- 15 